\title{
CORRIGENDUM
}

\section{The functional in vitro response to CD40 ligation reflects a different clinical outcome in patients with chronic lymphocytic leukemia}

C Scielzo, B Apollonio, L Scarfò, A Janus, M Muzio, E ten Hacken, P Ghia and F Caligaris-Cappio

Leukemia (2011) 25, 1794; doi:10.1038/leu.2011.191

Correction to: Leukemia (2011) 25, 1760-1767; doi:10.1038/ leu.2011.149; published online 28 June 2011

Since the publication of this article, the authors of the above paper have noticed errors that appeared within figures 1 and 3 of the online version of it.

The errors have now been rectified, and the correct article appears in this issue. The html and online pdf versions have also been rectified, and now carry the correct paper, which has been amended, and the correct figures now appear in the article.
The authors would like to apologise for any inconvenience caused. 